\title{
Correlation between static postural balance, falls and pick torque isokinetic of extensors and flexors of the knee in elderly
}

\author{
Marieli Ramos Stocco ${ }^{(1,2)}$, Deise Aparecida De Almeida Pires-Oliveira ${ }^{(3)}$, Laís Campus de Oliveira ${ }^{(1,2)}$, \\ Raphael Gonçalves de Oliveira ${ }^{(1,2)}$, Fábio Antônio Néia Martini ${ }^{(1)}$, Iransé Oliveira-Silva(3), Rodrigo Franco de Oliveira ${ }^{(3)}$
}

\begin{abstract}
:
Introduction: Declines of static postural balance and muscle strength, especially of lower limbs are strong predictors of falls in the elderly. Objective: The objective of this study was to identify the possible correlation between static postural balance, falls and isokinetic torque peak of knee extensors and flexors in the elderly. Methods: A cross-sectional study with anthropometric evaluation of static postural balance in unipodal limb support was performed using the force platform, flexural strength test and knee extension of the dominant limb using the isokinetic dynamometer and the application of a structured questionnaire on falls. They agreed to participate in the study 106 volunteers of both sexes through the signing of the free and informed consent. The data were treated in the Statistical Package for the Social Sciences program version 20.0. Results: There was a weak positive correlation between center of pressure (COP) area and peak flexion torque $(r=0.204, p=0.041)$ and extension $(r=0.228 ; p=0.022)$ of the knee, as well as peak extension $(r=0.319, p=0.001)$ and lateral mean $(r=0.324, p=0.001)$. A moderate positive correlation between COP area and anteroposterior velocity $(r=0.694, p=0.000)$ and lateral mean $(r=0.646 ; p=0.000)$ and strong positive correlation was found only between peak flexion torque and knee extension ( $r=0.719$, $p=0.000)$. Conclusion: There was a weak correlation between static postural balance and dominant lower limb muscle strength, and there was no correlation between falls and lower limb muscle strength, or between falls and static postural balance in the studied sample.
\end{abstract}

Keywords: Balance; Elderly; Falls; Isokinetic; Knee.

\section{INTRODUCTION:}

The biomechanical limitations associated with aging are strongly related to muscle strength and balance in the elderly. Generally, due to aging, there is a deterioration of several sense organs that directly affect these variables ${ }^{(1,2)}$. Postural imbalance is a limiting factor in the life of the elderly ${ }^{(3)}$ and added to the instability resulting from muscle weakness, end up compromising gait, Making it slow, cautious, drawn, accompanied by gingi, causing a greater propensity for falls $s^{(4,5)}$.

The maintenance of the postural balance is due to a set of reflexes that trigger responses based on visual, vestibular or somatosensory stimuli. Age-related changes in the sensorimotor system and the neuromuscular system negatively affect the performance of static and dynamic postural control, even in the healthy elderly ${ }^{(6,7)}$. These changes also affect the reaction time, the degree of oscillation of the body increases, even in simple positions, such as an upright posture, causing elderly individuals to suffer more oscillations ${ }^{(8)}$ and are more susceptible to falls.

The decrease of muscle strength, as well as of balance ${ }^{(9)}$, has consequences for the functional autonomy of this age group. In general, progressive loss of strength tends to leave older people unable to perform the simplest tasks of daily life, making them often dependent on those around them, which ultimately reduces the quality of life on a large scale of these individuals ${ }^{(10)}$.

Muscle weakness, impaired gait and impaired balance are relevant risk factors for falls in the elderly ${ }^{(11)}$. The incidence of falls is an important social issue as it can lead to reduced physical, social and psychological health problems. Among the consequences of the fall are: reduced functionality, loss of independence and, in some cases, death. In addition, falling leads to increased health costs and defines a series of social problems ${ }^{(2)}$. Thus, it is extremely important to evaluate postural balance, falls and muscle strength in the elderly, in order to elucidate the efficient alternatives that can be applied to fall prevention and rehabilitation after the same in the elderly. Therefore, we aimed to identify the correlation between static postural balance, falls and isokinetic torque peak of knee extensors and flexors in the elderly of a community in the interior of the State of Paraná, Brazil.

Corresponding Author: Rodrigo Franco de Oliveira. Address: Av. Senador Ramos Caiado 576, Anapolis, (GO), Brazil. CEP: $75040-320$. Phone: 0055 62 983466674

E-mail: rodrigo.oliveira@docente.unievangelica.edu.br

${ }^{1}$ Centro de Ciências da Saúde, Universidade Estadual do Norte do Paraná (UENP), Jacarezinho (PR), Brasil.

${ }^{2}$ Centro de Ciências Biológicas e da Saúde, Universidade Norte do Paraná (UNOPAR), Londrina (PR), Brasil.

${ }^{3}$ Centro Universitário de Anapolis - UniEVANGELICA, Anapolis (GO), Brasil.

Full list of author information is available at the end of the article.

Financing source: None.

Submission date 03 March 2017; Acceptance date 24 July 2017; Publication date 27 October 2017 


\section{METHODS}

\section{Participants}

The research was outlined as a cross - sectional study, with the proposal to evaluate the following variables: muscular strength and postural balance in healthy elderly with gold standard assessment instruments. 106 elderly people of both sexes participated in the study. The sample number was established based on published scientific articles on the subject whose methodology is close to that of the present study.

All the elderly were recruited in the local community. Inclusion criteria in this study were: age above 60 years, independence to perform activities of daily living (ADLs) and instrumental activities of daily living (IADLs), do not present functional limitations to walking or using support devices (bengal, walker, and crutches), have no physical, auditory, or visual impairment that impedes the performance of the tests, respond negatively to a questionnaire with self-reported questions regarding comorbidities to identify problems such as knee or hip osteoarthrosis, labyrinthine crises, orthopedic hip, knee or ankle surgeries that limit the performance of the balance tests, have the cognitive ability to correctly answer the questionnaires (score> 19 in the Mental State Mini Exam), not be considered sedentary IPAQ (International Physical Activity Questionnaire) - short version. The general exclusion criteria were: self-reported musculoskeletal and neural diseases or disorders, severe and chronic labyrinthitis; chronic diseases of the cardiovascular and respiratory systems, presence of any electronic or implanted metallic devices, such the a pacemaker.

To determine the level of physical activity, a short version of the IPAQ questionnaire was used by all volunteers. Participants were informed about the trial protocol and possible study risks and gave written consent prior to participation. In accordance with Resolution 196/96 of the National Health Council, the elderly agreed to participate voluntarily in the research, signing a Free and Informed Consent Form. The protocol and the consent term were previously approved by the Ethics Committee of UNOPAR - CEP - Unopar under $n^{\circ} 513.001$.

\section{Procedures}

The body mass was measured in a digital reading scale, Filizola brand, model ID 110 (FILIZOLA LTDA, Recife, Brazil), with an accuracy of $0.1 \mathrm{~kg}$ and the stature was measured with an aluminum stadiometer with an accuracy of $0.1 \mathrm{~cm}$, according to the procedures described By Gordon; Chumlea; Roche ${ }^{(12)}$. From these measurements, the body mass index (BMI) was calculated by means of the relationship between body mass and height squared, with body mass expressed in kilograms $(\mathrm{kg})$ and height in meters $(\mathrm{m})$. The elderly were classified according to the cut-off points recommended by the Pan American Health Organization (PAHO) in the Health, Welfare and Aging (SABE) project that surveyed Latin American countries, including Brazil: low weight $\left(\mathrm{BMI}<23 \mathrm{~kg}\left(\mathrm{BMI}<30 \mathrm{~kg} / \mathrm{m}^{2}\right)\right.$, normal weight
$\left(23<\mathrm{BMI}<28 \mathrm{~kg} / \mathrm{m}^{2}\right)$, pre-obesity $\left(28<\mathrm{BMI}<30 \mathrm{~kg} / \mathrm{m}^{2}\right)$ and obesity.

A questionnaire structured in the form of an interview was applied to know the number of falls suffered by the individual in the last year. The questionnaire contained two simple questions concerning the number of falls in the last six months and the last year.

After the familiarization with the instrument and experimental protocol, as shown in Figure 1, the participants performed the postural balance test in unipodal support with the lower limb of preference over a force platform BIOMEC400 (EMG System do Brasil Ltda, SJCampos, Brazil), three 30-second attempts were performed, with rest of 30 seconds between each. Statistical analyzes were performed using the mean number of attempts. The protocol was standardized for the task: bare feet, loose and relaxed arms next to the body and cephalic follow-up positioned horizontally to the ground plane. Each participant directed his gaze to a fixed target (black cross $=14.5 \mathrm{~cm}$ height $X 14.5 \mathrm{~cm}$ width $X 4 \mathrm{~cm}$ thick), positioned on the wall at a distance of 2.5 meters and at eye level. For balance evaluation, soil reaction force signals from the platform measurements were collected at a $100 \mathrm{~Hz}$ sampling. All force signals were filtered with a second-order Butterworth low-pass filter at $35 \mathrm{~Hz}$. The signals were converted by means of a stabilogram analysis, compiled with the platform software's own MATLAB routines (The Mathworks, Natick, MA). The main equilibrium parameter computed was center of pressure COP (Velo COP) oscillation velocity, in the anteroposterior (A/P) and mid-lateral $(\mathrm{M} / \mathrm{L})$ and $\mathrm{COP}\left(\mathrm{cm}^{2}\right)$ directions (Figure 1$)$.

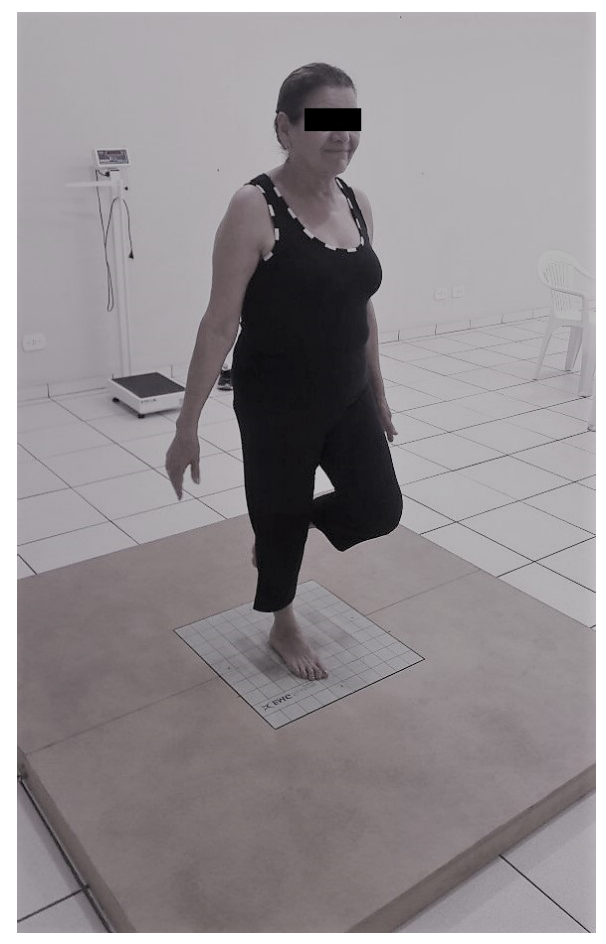

FIGURE 1. Evaluation on the force platform 
The dominant lower limb muscle strength was measured using a Biodex model Multi-Joint Pro isokinetic dynamometer at an angular velocity of 60 per second, with peak torque and total muscle work being analyzed. The evaluation was performed with the individual sitting with the chair positioned at 85 o of hip flexion, axis of rotation of the equipment aligned to the center of the knee joint (lateral epicondyle), belts positioned in the trunk and (crusaders) pelvic region, around the Thigh of the contralateral limb and ankle homolateral to the limb evaluated, according to the protocol of Potulski et al. (2011) (13).

Prior to the dynamometer test, the instrument was properly "calibrated" and ready to store the data of the volunteers following the manufacturer's standards correctly. Before the start of the test, they performed a warm up on a Monark brand ergometer for five minutes, without load. Soon after, they were taken to the isokinetic chair to begin the evaluation.

Following the manufacturer's standards, the rater should stabilize the individual in the chair according to his or her biotype, cross belt in the thoracic region, a belt in the pelvic region, and a non-dominant leg belt (quadriceps height). The dominant leg will be attached to the lever arm of the dynamometer, with the support cushion two centimeters from the heel and the dynamometer axis parallel to the axis of the volunteer's knee joint. The evaluator used the device as a model for demonstration of the technique and adequate form of execution. After being properly instructed, the individual had a brief familiarization with the dynamometer, with respect to strength and range of motion, as shown in Figure 2.

The evaluation was performed in the concentric/concentric mode, that is, to test the extensors, the knee should start from 90 은 to 0 , and to test the flexors the knee should start from 0 ㅇ to 90 . The angular velocity will be of 60 \% / s, being realized five repetitions, having an interval of 30 seconds between the three series.

\section{Statistical Analyzes}

A descriptive analysis of the data was performed, expressed as mean and standard deviation. To verify the normality of data distribution, the Kolmogorov-Smirnov test was performed. The Mann-Whitney test for independent samples was used to compare the genders. The correlation between the analyzed variables was evaluated using the Spearman correlation test. The confidence interval allowed in all tests was 95\% ( $P<0.05)$. The data were treated in the Statistical Package for the Social Sciences (SPSS Corp., Chicago, IL, USA), version 20.0.

\section{RESULTS}

The characteristics of the sample are set out in TABLE 1. The mean age of the evaluated individuals was $68.58 \pm 5.86$. All assessed were right-handed in the dominant lower limb, thus only the right lower limb was assessed. The data represented in TABLE 1 show a weight of $67.40 \pm 11.99$ kilograms and a height of $1.62 \pm 0.07$ meters and $\mathrm{BMI}$ of $25.58 \pm 3.68$, which characterizes the general sample with normal weight $\left(23<\mathrm{BMI}<28 \mathrm{~kg} / \mathrm{m}^{2}\right)$ according to the cut-off points recommended by the Pan American Health Organization (PAHO) in the Health, Welfare and Aging (SABE) project (Table 1 ).

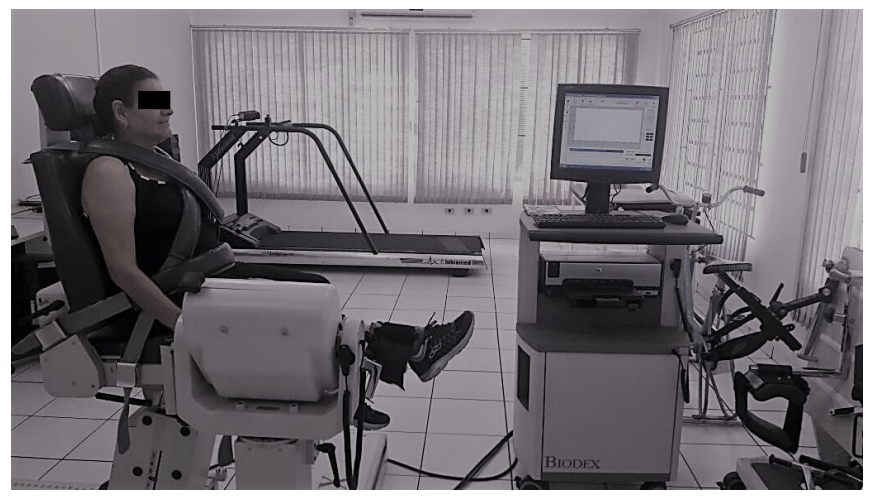

FIGURE 2. Evaluation in the isokinetic dynamometer

TABLE 1. Characteristics of the sample

\begin{tabular}{|c|c|c|c|c|}
\hline & Total $(\mathrm{N}=106)$ & Women $(n=80)$ & $\begin{array}{c}\text { Men } \\
(n=26)\end{array}$ & $\begin{array}{c}P \\
\text { Value }\end{array}$ \\
\hline Weight (Kg) & $67.40 \pm 11.99$ & $69.16 \pm 9.64$ & $76.70 \pm 13.38$ & $0.000 * *$ \\
\hline Height (m) & $1.62 \pm 0.07$ & $1.60 \pm 0.06$ & $1.66 \pm 0.08$ & $0.000 * *$ \\
\hline IMC & $25.58 \pm 3.68$ & $24.93 \pm 3.50$ & $27.41 \pm 3.60$ & $0.002 * *$ \\
\hline Fall & $0.49 \pm 0.93$ & $0.47 \pm 0.91$ & $0.56 \pm 0.99$ & 0.425 \\
\hline PT. Extension & $91.19 \pm 28.96$ & $83.65 \pm 21.80$ & $112.81 \pm 35.92$ & $0.001 * *$ \\
\hline PT. Flexion & $47.19 \pm 17.70$ & $42.67 \pm 15.22$ & $60.16 \pm 18.19$ & $0.001 * *$ \\
\hline Area do COP & $105.84 \pm 483.32$ & $68.36 \pm 252.04$ & $213.40 \pm 854.63$ & 0.952 \\
\hline Vel. AP & $6.46 \pm 5.56$ & $6.02 \pm 4.91$ & $7.70 \pm 7.04$ & 0.471 \\
\hline Vel. ML & $9.84 \pm 26.81$ & $9.39 \pm 28.41$ & $11.16 \pm 22.10$ & 0.454 \\
\hline
\end{tabular}

Note: ${ }^{*} \mathrm{p}<0,01 ;{ }^{*} \mathrm{p}<0,05 ; \mathrm{IMC}=$ Índice de Massa Corporal; PT. Extension = Peak extension torque; PT. Flexion = peack flexion torque; COP area = Pressure Center Displacement area; Vel. AP = Antero Posterior Velocity; Vel. $\mathrm{ML}=$ Mean Lateral Velocity. 
With regard to the variables analyzed, a negligible positive correlation between falls and peak flexion torque $(r=0.213$, $p=0.040$ ), a weak positive correlation between COP area and peak flexion torque $(r=0.204, p=0.041)$ and extension ( $r=0.228, p=0.022$ ) of the knee, and also between the peak of the knee extension and anteroposterior velocity $(r=0.319$, $p=0.001)$ and the lateral mean $(r=0.324, p=0.001)$. A moderate positive correlation occurred between COP area and anteroposterior velocity $(r=0.694 ; p=0.000)$ and lateral mean $(r=0.646 ; p=0.000)$, and mean lateral and anteroposterior velocity $(r=0.710 ; p=0.000)$ as evidenced by TABLE 2 . So the hypothesis of the study that would be an inverse correlation between muscle strength and oscillation in the force platform was not confirmed, that is, in general the data are showing that the higher the force, the more oscillation in the force platform, which presupposes a equilibrium deficit, which can be supposedly explained by rigidity conditions, for example. However, new studies are needed to analyze this variable along with static postural balance on the platform of muscle strength and lower limb strength through the isokinetic.

\section{DISCUSSION}

Detection of fall risk factors is essential to implement effective strategies tailored specifically to fall prevention ${ }^{(14)}$. Some risk factors for falls are irreversible, while others are potentially modifiable with appropriate interventions ${ }^{(15-17)}$. Three of the most common modifiable intrinsic risk factors are muscle weakness, balance deficit and gait instability ${ }^{(14,18-20)}$.

Misic et al. ${ }^{(19)}$ evaluated the peak torque of flexors and knee extensors of fifty-five elderly at 60 을 120 o by means of an isokinetic dynamometer. Their results evidenced after intervention comparing two training programs (cardiovascular endurance and flexibility/balance) that in all subjects improved knee torque peak for flexion (47.73 \pm 22.45$)$ and extension (108.41 \pm 46.81$)$ For both speeds tested.

In this cross-sectional study, peak torque values for flexors $(47.19 \pm 17.70)$ and extensors $(91.19 \pm 28.96)$ of dominant lower limbs evaluated by isokinetic dynamometry were very close To those found by Misic et al. ${ }^{(19)}$ in spite of the inclusion of active and sedentary, trained and untrained individuals in the sample, while Misic used the inclusion criterion for the research for the cutoff point of 45 (out of a total of 54 points) in the Berg Balance Scale .

Mesquita ${ }^{(10)}$ evaluated sixty-three elderly people through the force platform after training programs involving Pilates and Proprioceptive Neuromuscular Facilitation and control group, in bipodal support, - COP Area (102.6 \pm 100.6$)$, Vel. AP (21.05 \pm 12.01$)$, Vel. ML (14.06 \pm 8.00$)$. This study, although it evaluated the balance in unipodal support, approached these results - COP area (105.84 \pm 483.32$)$, Vel. AP (6.46 \pm 5.56$)$, Vel. ML (9.84 \pm 26.81$)$.

The results of the present study show that there was a weak positive correlation between COP area and peak torque flexion and extension, and also between knee peak extension torque change and anteroposterior and meanlateral velocity. A moderate positive correlation occurred between COP area and anteroposterior and meanlateral velocity. And finally the best correlation found (strong positive correlation) was between peak flexion torque and knee extension.

This result indicates that the higher the area of COP, ie the area of oscillation of the force platform (which presupposes, equilibrium deficits), the greater the force of flexion and extension of upper limbs, that is, the correlation between equilibrium postural and muscle strength of knee flexors and extensors was weak. The correlation between knee peak extension torque (extension force) and anteroposterior and

TABLE 2. Correlation between study variables

\begin{tabular}{|c|c|c|c|c|c|c|c|}
\hline & & Fall & PT. Extension & PT. Flexion & Area de COP & Vel. AP & Vel. ML \\
\hline \multirow{2}{*}{ Fall } & $r$ & - & & & & & \\
\hline & $p$ & - & & & & & \\
\hline \multirow{2}{*}{ PT. Extension } & $r$ & -0.128 & - & & & & \\
\hline & $p$ & 0.219 & - & & & & \\
\hline \multirow{2}{*}{ PT. Flexion } & $r$ & $0.213 *$ & $0.719 * *$ & - & & & \\
\hline & $p$ & 0.040 & 0.000 & - & & & \\
\hline \multirow{2}{*}{ Area do COP } & $r$ & 0.031 & $0.228 *$ & $0.204^{*}$ & - & & \\
\hline & $p$ & 0.775 & 0.022 & 0.041 & - & & \\
\hline \multirow{2}{*}{ Vel. AP } & $r$ & -0.010 & $0.319 * *$ & 0.189 & $0.694^{* *}$ & - & \\
\hline & $p$ & 0.922 & 0.001 & 0.059 & 0.000 & - & \\
\hline \multirow{2}{*}{ Vel. ML } & $r$ & 0.025 & $0.324 * *$ & 0.154 & $0.646^{* *}$ & $0.710 * *$ & - \\
\hline & $p$ & 0.816 & 0.001 & 0.124 & 0.000 & 0.000 & - \\
\hline
\end{tabular}

Note: ${ }^{*} \mathrm{p}<0,01 ; * \mathrm{p}<0,05 ; \mathrm{IMC}=$ Índice de Massa Corporal; PT. Extension = Peak extension torque; PT. Flexion = peack flexion torque; COP area = Pressure Center Displacement area; Vel. AP = Antero Posterior Velocity; Vel. $\mathrm{ML}=$ Mean Lateral Velocity. 
meanlateral displacement velocity on the force platform was also weak.

Another finding was that the COP area and anteroposterior and meanlateral displacement velocity presented a moderate correlation, indicating that a greater velocity of anteroposterior and meanlateral displacement on the platform is not always accompanied by a large displacement area in the same. Finally, as expected, the correlation between peak flexion torque and knee extension was strong, showing that both are directly proportional magnitudes.

Thus the hypothesis of the study that would expect an inverse correlation between muscle strength and oscillation in the force platform was not confirmed, that is, in general the data are showing that the higher the force there is more oscillation in the force platform assuming larger deficits of balance.

To date, no correlation study has been found between the analyzed variables that uses a methodological evaluation close to this one to compare them. More research is needed to determine which relationship and which physical fitness components, when added to a workout, are effective in preserving falls in the elderly.

\section{CONCLUSION}

Given the above, there is a weak correlation between postural balance and muscle strength and there is no correlation between falls and muscle strength or falls and balance in the sample studied. Therefore, we recommend that further studies include larger samples and interventions that compare and/or these variables to other components of physical fitness in order to understand mechanisms that lead the elderly to suffer falls. This will help elucidate the efficient alternatives that can be applied to fall prevention and rehabilitation after the same in the elderly.

\section{AUTHORS' CONTRIBUTIONS}

MRS, DAPO contributed with the preparation of the study design and development, acquisition and analysis of data, and approve the final version; LCO participated in the conception of the article, tabulation of the data collected, and the processes to obtain the Research Ethics Committee involving human beings; RGO contributed to the preparation of the study and its development, data acquisition and analysis, critical review of the final content, and approval of the final version. FANM and IOS contributed with the development of the study, data acquisition, and approve the final version; RFO contributed with the preparation of the study design and development, acquisition and analysis of data, review critically the final content, and approve the final version.

\section{CONFLICTS OF INTEREST}

The authors declare that they have no conflicts of interest in the research.

\section{AUTHORS' INFORMATION}

Marieli Ramos Stocco: Master candidate on Centro de Ciências da Saúde da Universidade Estadual do Norte do Paraná (UENP), Jacarezinho (PR), Brasil, marieli.stocco@uenp.edu.br;

Deise Aparecida De Almeida Pires-Oliveira: Doctor and professor on Centro Universitário de Anapolis - UniEVANGELICA, Anapolis (GO), Brazil, deisepyres@gmail.com
Lais Campos de Oliveira: Doctorate on Centro de Ciências Biológicas e da Saúde, Universidade Norte do Paraná (UNOPAR), Londrina (PR), Brasil and professor of Centro de Ciências da Saúde da Universidade Estadual do Norte do Paraná (UENP), Jacarezinho (PR), Brasil, oliveiralc@uenp.edu.br;

Raphael Gonçalves de Oliveira: Doctor and professor on Centro de Ciências da Saúde da Universidade Estadual do Norte do Paraná (UENP), Jacarezinho (PR), Brasil, rgoliveira@uenp.edu.br;

Fábio Antônio Néia Martini: Doctor and professor on Centro de Ciências da Saúde da Universidade Estadual do Norte do Paraná (UENP), Jacarezinho (PR), Brasil, famartini@uenp.edu.br;

Iransé Oliveira Silva: Doctor and professor on Centro Universitário de Anapolis - UniEVANGELICA, Anapolis (GO), Brazil, iranse.silva@unievangelica.edu.br.

Rodrigo Franco de Oliveira: Doctor and professor on Centro Universitário de Anapolis - UniEVANGELICA, Anapolis (GO), Brazil, rfrancoli@yahoo.com.br.

\section{REFERENCES}

1. Kim JI, Choe MA, Chae YR. Prevalence and Predictors of Geriatric Depression in Community-Dwelling Elderly. Asian Nurs Res (Coreano Soc Nurs Sci). 2009;3(3):121-9.

2. Park J, Yim J. A New Approach to Improve Cognition, Muscle Strength, and Postural Balance in Community-Dwelling Elderly with a 3-D Virtual Reality Kayak Program. Tohoku J Exp Med. 2016;238(1):1-8.

3. Macedo DO, Freitas LM, Scheicher ME. Preensão palmar e mobilidade funcional em idosos com diferentes níveis de atividade física. Fisioter Pesq. 2014;21(2):151-155.

4. Victor LGV, Oliveira MR, Teixeira DdC, Paes MA, Fujisawa DS, Bispo $\mathrm{NdNdC}$, et al. Postural control during one-leg stance in active and sedentary older people. Motriz: Rev. Educ. Fis. 2014;20(3):339-345.

5. Vaghetti CAO, Roesler $\mathrm{H}$, Andrade A. Tempo de reação simples auditivo e visual em surfistas com diferentes níveis de habilidade: comparação entre atletas profissionais, amadores e praticantes. Rev Bras Med Esporte. 2007;13(2):81-85.

6. Horak FB. Postural orientation and equilibrium: what do we need to know about neural control of balance to prevent falls? Age Ageing. 2006; 35 Suppl 2:ii7-ii11.

7. Lesinski M, Hortobágyi T, Muehlbauer T, Gollhofer A, Granacher U. Effects of Balance Training on Balance Performance in Healthy Older Adults: A Systematic Review and Meta-analysis. Sports Med. 2015;45(12):1721-38.

8. Silva NL, Farinatti PdTV. Influência de variáveis do treinamento contraresistência sobre a força muscular de idosos: uma revisão sistemática com ênfase nas relações dose-resposta. Rev Bras Med Esporte. 2007;13(1):6066.

9. Côrtes GG, Silva VF. Manutenção da Força Muscular e da Autonomia, em Mulheres Idosas, Conquistadas em Trabalho Prévio de Adaptação Neural. Fitness \& performance journal. 2005;2(1):107-116.

10. Mesquita L, Carvalho F, Freire L, Neto O, Zângaro R. Effects of two exercise protocols on postural balance of elderly women: a randomized controlled trial. BMC Geriatrics. 2015;15(61):1-9.

11. Lohne-Seiler H, Kolle E, Anderssen S, Hansen B. Musculoskeletal fitness and balance in older individuals (65-85 years) and its association with steps per day: a cross sectional study. BMC Geriatrics. 2016;16(6):1-11.

12. Gordon CC, Chumlea WC, Roche AP. Stature, recumbent length, and weight. In: Lohman TG; Roche AF; Martorell R, ed. Anthropometric Standardization Reference Manual. Champaign, Illinois: Human Kinetics Books; 1988:3-8.

13. Potulski AP, Balssera DK, Vidmar MF, Wibelinger LM. Pico de torque muscular de flexores e extensores de joelho de uma população geriátrica. Rev Bras de Ciên Saúde. 2011;28(9):25-30. 
14. Bloch F, Thibaud M, Tournoux-Facon C, Breque C, Rigaud AS, Dugue B, Kemoun G. Estimativa dos fatores de risco para quedas em idosos: pode meta-análise dar uma resposta válida? Geriatr Gerontol Int. 2013;13(2):250-263.

15. Axer H, Axer M, Sauer H, Witte OW, Hagemann G. Falls and gait disorders in geriatric neurology. Clin Neurol Neurosurg. 2010; 112 (4): 265-274.

16. Rubenstein $L Z$, Josephson KR. A epidemiologia de quedas e síncope. Clin Geriatr Med. 2002;18(2):141-158.

17. American Geriatrics Society, British Geriatrics Society, American Academy of Orthopaedic Surgeons Painel de Prevenção Falls. Orientação para prevenção de quedas em idosos. J Am Geriatr Soe. 2001;
18. American Geriatrics Society, British Geriatrics Society, American Academy of Orthopaedic Surgeons Painel de Prevenção Falls. Orientação para prevenção de quedas em idosos. J Am Geriatr Soe. 2001;49(5):664672.

19. Granacher L, Muehlbauer t, Zahner G, Gollhofer A, Kressig RW. Comparação das abordagens tradicionais e recentes na promoção do equilíbrio e força em adultos mais velhos. Sports Med. 2011;41(5):377400.

20. Misic MM, Valentine RJ, Rosengren KS, madeiras JA, Evans EM. Impact of Training Modality on Strength and Physical Function in Older Adults. Gerontologia. 2009;55(4):411-416. 